\title{
EL LÉXICO ARGÓTICO EN EL VOCABULARIO DE MEXICANISMOS DE JOAQUÍN GARCÍA ICAZBALCETA
}

\author{
IVo BuzeK \\ Universidad Masaryk ${ }^{1}$
}

\section{Resumen}

El objetivo del artículo es estudiar cómo está tratado y qué tipo de léxico de las capas más bajas de la sociedad mexicana de los tiempos del porfiriato está presente en el Vocabulario de mexicanismos de Joaquín García Icazbalceta, desgraciadamente inconcluso. Se estudiará su estructura (léxico patrimonial, préstamos, procesos lexicogenéticos y de cambio semántico presentes) y se prestará atención a las fuentes que utilizó el autor para avalar las voces en cuestión. El diccionario se lee aquí como una fuente que puede servir para el estudio de la historia del argot mexicano a finales del siglo xix, tomando en consideración que un diccionario es sobre todo un corpus lexicológico que dentro de los límites que naturalmente tiene da fe de la realidad social de sus tiempos. La historia del habla de los bajos fondos de la sociedad mexicana es una de las lagunas en la bibliografía sobre la diacronía del español mexicano y el presente texto procura ayudar a ir llenando este vacío en el área de conocimiento.

Palabras clave: Argot carcelario, lexicología y lexicografía históricas, formación de palabras, cambio semántico, español de México.

\section{ARGOTIC LEXICON IN THE VOCABULARIO DE MEXICANISMOS BY JOAQUÍN GARCÍA ICAZBALCETA}

\begin{abstract}
The aim of the paper is to study how the lexicon of lower layers of Mexican society in the Porfirian period (second half of the 19th century) is treated in the Vocabulary

1 Una primera versión de este trabajo fue presentada de forma muy reducida como comunicación en el congreso internacional «Tradiciones discursivas y tradiciones idiomáticas en la historia del español moderno» (26-28 de septiembre de 2018, Universidad de Sevilla). Se inscribe dentro del proyecto «Corpus diacrónico para el estudio de las actitudes lingüísticas en América y España en los siglos XVIII y XIX» (FFI2016-76874-P), concedido por el Ministerio de Economía y Competitividad del Gobierno de España, y cuenta asimismo con el apoyo de la Facultad de Filosofía y Letras de la Universidad Masaryk.
\end{abstract}

Fecha de recepción: 3 de diciembre de 2018

Fecha de aceptación: 13 de mayo de 2019 
of Mexicanisms by Joaquín García Icazbalceta, unfortunately unfinished. The structure of the argotic lexicon (patrimonial lexicon, loans, lexicogenetic processes and semantic changes) will be studied in detail and attention will be paid to sources used by the author to document the voices in question. The dictionary is taken here as a source that can be used for the study of the history of Mexican slang at the end of the 19th century, taking into consideration that a dictionary is primarily a lexicological corpus that, within the limits that naturally has, testifies the social reality of its times. The history of the speech of the underworld of Mexican society is one of the gaps in the literature on the diachrony of Mexican Spanish and the present paper seeks to help fill in this gap.

Keywords: Prison slang, historical lexicology and lexicography, word formation, semantic change, Mexican Spanish.

\section{INTRODUCGión}

En la historia del español mexicano y en su historiografía hay obras y áreas de las que existen nociones generales, es decir, «se sabe de ellas», pero que, por una razón u otra, se obvian y hasta el momento han sido poco estudiadas por los investigadores. Una de ellas es el léxico argótico desde su perspectiva diacrónica; otra sería el Vocabulario de mexicanismos (1899) de Joaquín García Icazbalceta. El objetivo de la presente contribución será procurar unir las dos áreas y estudiar cómo está tratado y qué tipo de léxico argótico está presente en este famoso diccionario inconcluso.

En lo que se refiere al argot, prestaremos atención a su estructura y a sus procesos lexicogenéticos, teniendo en cuenta también los argots hispánicos contemporáneos de la época del autor (sobre todo el argot del español europeo) y las hablas marginales hispanas de épocas anteriores para apreciar la continuidad o los rasgos que ya serían propiamente mexicanos.

En cuanto al valor del diccionario de García Icazbalceta como fuente, nos fijaremos en las áreas del léxico de marginales y marginados mexicanos que recogió el autor y en las fuentes documentales en las que se había basado. Como es sabido, y como recordaremos a continuación, aunque el Vocabulario nació como un complemento del diccionario académico, no se trataba de una colección de palabras pintorescas como en casos de otros varios diccionarios latinoamericanos diferenciales de la época, sino de una aportación decidida del español mexicano al caudal del léxico hispánico general, representado entonces por el diccionario de la Academia española. Por tanto, será interesante ver qué términos propios o relacionados con las clases bajas mexicanas del siglo xix escogió el lexicógrafo, qué criterios podían haberle guiado y qué fuentes había utilizado para avalar las voces seleccionadas.

En síntesis, esperamos con el presente estudio, y con los que vendrán a continuación, que podamos ayudar a llenar por lo menos algunos huecos en 
blanco que hay de momento en el mapa de la evolución del léxico diafásica y diastráticamente marcado en la historia del español mexicano.

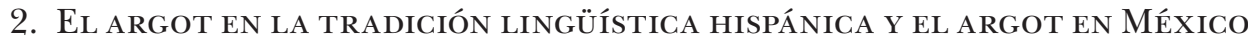

Como es bien sabido, el argot es en la tradición lingüística hispánica un término ambiguo que se ha utilizado o en el sentido general de «sociolecto» o en el de «sociolecto de las clases criminales». Pero también puede ser definido de manera más amplia como un léxico coloquial muy expresivo impregnado con giros vulgares y malsonantes y a veces con connotaciones ofensivas (Buzek, 2011). En este sentido, el término argot hace alusiones (o da por sobreentendido) que se trataría de un sociolecto originado, en principio, entre las clases bajas dedicadas a actividades criminales que ha salido de su área originaria del dominio y se ha difundido en el registro coloquial de la lengua, fuera de su ámbito restringido originario, transformándose en el llamado «argot común» (Sanmartín Sáez, 1998 y 2006). No obstante, en este estudio pretendemos seguir el sentido más restringido posible del término, es decir, el del «sociolecto de la delincuencia», aunque somos conscientes de que este no siempre se puede separar con facilidad del «argot común». Estamos seguros de que el Vocabulario podría aportar datos interesantes sobre otros sociolectos mexicanos de la época también, pero este sería tema para otros trabajos.

En el ámbito de las fuentes del español mexicano, las primeras muestras del argot de la delincuencia las encontramos en obras literarias del siglo xix y en glosarios que a veces acompañaban sus ediciones, como sería el caso de El Periquillo Sarniento, de José Joaquín Fernández de Lizardi (Davies, 1956; Buzek, 2017). El argot de la delincuencia mexicana cuenta asimismo con una tradición lexicográfica que data desde la primera mitad del siglo xx (Aguilar, 1941; Franco, 2014; Amor, 2014; Chabat, 1964; o Colín Sánchez, 1997), aunque es cierto que son repertorios que metodológicamente serían muchas veces discutibles. Ahora bien, es plausible $-\mathrm{y}$ hay que reconocerloque para el argot mexicano actual la situación ha cambiado bastante y se han publicado varios estudios filológicos rigurosos sobre él (Lara, 1992; Hernández Martínez, 2002 y 2004; entre otros). No obstante, se siguen echando de menos estudios dedicados a su evolución. Como ya hemos dicho, existen trabajos sobre el argot en obras de determinados escritores, como el Pensador Mexicano (López López, 1931; Davis, 1950, 1956 y 1958; Frago Gracia, 2014; Buzek, 2017) u otros autores costumbristas de la época (Buzek, 2018 y 2019) y sobre el argot en los primeros diccionarios diferenciales del español mexicano (Buzek, 2015; Buzek y Gazdíková, 2017), pero en general no suelen sobrepasar el nivel de primeras aproximaciones o estudios parciales concretos. Creemos que harán falta todavía muchos estudios para poder 
trazar una visión de conjunto que podría documentar la evolución de las hablas marginales en el español mexicano desde los primeros tiempos de la colonia, pasando por la época de la consolidación del español mexicano como variedad con rasgos dialectales propios (Company, 2012) hasta la actualidad. Las fuentes de su estudio serían tanto las obras literarias, sobre todo por la facilidad para su acceso, como la documentación archivística que en general está por estudiar. La tercera parcela de fuentes serían los diccionarios (monolingües generales, diferenciales de mexicanismos, de argot y/o de hablas populares) que, como ya hemos anticipado, muchas veces deben ser tratados con sumo cuidado para interpretar adecuadamente los datos que traen. Pero como argumenta Lara (1997), los diccionarios son córpora léxicos que reflejan la realidad social de la época en la que nacieron y, también, como recuerda Prieto García-Seco (2014), el mismo valor lo pueden tener también para los estudios históricos sobre el léxico. Y como veremos a continuación, el Vocabulario de García Icazbalceta no es una excepción en este aspecto.

\section{El Vocabulario de meXicanismos en CONTEXto}

La mayoría de los diccionarios de americanismos del siglo xix (tanto los generales como los de regiones o países latinoamericanos concretos) solían ser correctivos, es decir, estaban dedicados a recoger barbarismos y demás usos no recomendables del léxico español en las variedades latinoamericanas. En este sentido, el Vocabulario de García Icazbalceta es muy distinto, ya que nació a partir de un encargo que la Real Academia Española le había hecho a la Academia mexicana asociada para que revisara la edición del DRAE-1869 y le enviara sus propuestas de mexicanismos para la edición próxima, que sería la de 1884. De las mil trescientas papeletas que le envió la Academia mexicana bajo la dirección de García Icazbalceta fue aceptada la mitad de ellas, aproximadamente.

Ahora bien, García Icazbalceta, el principal promotor del proyecto, como se diría hoy día, no se sentía satisfecho con el resultado y en el texto introductorio al tomo in de las Memorias de la Academia Mexicana de la Lengua (1886) que acompañaba la lista completa de las papeletas enviadas - texto que luego se reimprimiría como introducción de su Vocabulario (García Icazbalceta, 1899) póstumo - argumentaba apasionadamente a favor de los regionalismos y de la necesidad de que se recogieran en el Diccionario académico. Este no lo percibía como un repertorio «oficial» de la Academia española al que los regionalismos ultramarinos tenían entonces un acceso restringido, sino como un repertorio del español «correcto» a nivel general y, desde su punto de vista, su español mexicano en el uso culto era en principio tan correcto como el peninsular (Fernández Gordillo, 2010: 119). Si decimos que el diccionario de García Icazbalceta fue contrastivo, debemos 
tener en cuenta que el elemento de contraste no fue el español europeo, sino el español mexicano en su uso neutro o culto. Como afirma Bürki (2014: 206): «dicha comparación contrastiva se realiza dentro de la igualdad jerárquica que éstas [las variedades del español] tienen, otorgándoles a todas las variedades el mismo valor lingüístico».

Otra característica peculiar del diccionario de García Icazbalceta son las citas que ejemplificaban los usos, es decir, fue un diccionario con «autoridades». Por tanto, sería sumamente interesante tanto para la historiografía lingüística como para la historia del léxico ver qué fuentes había escogido el lexicógrafo para autorizar las voces propias, en principio, de las clases bajas y de los grupos criminales de la sociedad mexicana de su época.

4. El léXico argótico en el Vocabulario de mexicanismos. Estructura y FUENTES

En primer lugar, vamos a prestar atención a la estructura del léxico argótico presente en las páginas del Vocabulario de mexicanismos, es decir, si se trataba del léxico patrimonial o de préstamos, qué principales procesos lexicogenéticos aparecían en él y si podemos hablar de continuidad con el argot español de épocas anteriores o si estamos ante formaciones nuevas, nacidas ya en el ámbito del español mexicano. En este aspecto nos ayudaría su presencia en las fuentes lexicográficas del argot español (Alonso Hernández, 1977; Chamorro, 2002; Salillas, 1896), del argot mexicano (Aguilar, 1941; Franco, 2014; Amor, 2014; Chabat, 1964; Colín Sánchez, 1997), en los diccionarios diferenciales del español en América $(D A)$ y del español mexicano $(D M)$, y en el diccionario integral del español mexicano (DEM).

La siguiente área de interés serían las fuentes, es decir, qué fuentes había utilizado el lexicógrafo para avalar los términos argóticos y por qué las habría escogido. En nuestro reciente estudio sobre las actitudes lingüísticas en el Vocabulario de mexicanismos (Buzek, 2020) hemos visto que García Icazbalceta se mostraba relativamente tolerante con voces diafásica y distráticamente marcadas si estas aparecían en fuentes literarias, sobre todo en la literatura costumbrista, pero que las percibía de manera sumamente negativa si las encontraba en fuentes no literarias o si procedían de «fuentes orales», y en estos casos no vacilaba en señalarlas como «disparates» (fiero o desapartar).

Y finalmente sería interesante ver qué ámbitos del léxico argótico encontraron su cabida en el Vocabulario, es decir, qué profesiones de la delincuencia o qué áreas del argot en su sentido restringido llegaron a quedar representadas en el diccionario y por qué.

Para no sobrecargar el texto con largas muestras de artículos lexicográficos del Vocabulario que posiblemente entorpecerían la lectura, hemos 
decidido recoger al final del texto, en un anexo, todos los artículos de los que nos hemos ocupado en nuestro estudio. Creemos que es importante y de sumo interés que el lector pueda consultar dichos artículos y ver los distintos componentes de su microestructura, sobre todo las definiciones y las citas textuales que traen.

\subsection{Mexicanismos exclusivos o continuidades con el argot español}

Hemos seleccionado 36 términos en total que, según la opinión del lexicógrafo, formaban parte del argot de la delincuencia mexicana de su época. Si los contrastamos con repertorios lexicográficos del argot de la delincuencia española, tanto de la germanía áurea (Alonso Hernández, 1977; Chamorro, 2002) como la contemporánea de su época (Salillas, 1896), notamos ecos de un pasado común, pero, en general, podemos confirmar que el argot de la delincuencia mexicana ya estaba plenamente constituido como un sociolecto propiamente autónomo o «nacional». Las reminiscencias del pasado serían las voces golpe 'pestillo' y de allí por metáfora 'portero en la cárcel'; abrigadero 'lugar seguro y protegido', derivado claramente de abrigo 'amparo, protección'; burlote 'partida de juego con poco valor', documentada en Salillas (1896) y relacionada con burlotero, término del argot de jugadores de los Siglos de Oro (Chamorro 2002); y araña 'prostituta'. Otros términos, provenientes esta vez del léxico administrativo carcelario, conocido y usado también por los presos, pero que muestran diferencias en el significado en comparación con las fuentes españolas, serían compurgar y evadirse.

\subsection{Estructura y procesos lexicogenéticos}

En lo que se refiere a la estructura y a los procesos lexicogenéticos que hemos documentado, es preciso advertir que los datos no son nada sorprendentes y se corresponden a grandes rasgos con los resultados de otras investigaciones anteriores. El argot de la delincuencia siempre ha sido urbano, así que su léxico era en general patrimonial hispano y, si había indigenismos, eran muy pocos y se trataba ya de préstamos totalmente asimilados en el español mexicano popular de la época (coyote, conclapache). Prueba de la asimilación serían derivados como coyotear, formado a partir de coyote 'intermediario fraudulento'. Otro préstamo adaptado, esta vez de origen francés y acompañado también por su derivado hispano, sería gurupié (de croupier) 'el que baraja en las casas de juego, y recoge y paga las apuestas', y de allí gurupiada 'paga ó gratificación que se da al gurupié'.

En cuanto a los procesos de la formación de palabras, no hemos encontrado ningún ejemplo de composición, pero la derivación, en concreto la sufijación, es bastante frecuente. En general prevalece la derivación nominal sobre la verbal, puesto que serían doce casos de la derivación nominal frente 
a cuatro de la verbal. No es sorprendente que prevalezcan los sustantivos; si definimos el argot como un sociolecto, es natural que la mayoría sean nombres que designen objetos y realidades propios del ámbito de un determinado grupo social.

Como ya hemos dicho, los sustantivos son once y son los siguientes: abrigadero 'lugar donde se escondían los delincuentes'; abrigador 'encubridor de delincuentes'; afanaduría 'en los hospitales, cárceles e inspecciones de policía, pieza en que se reciben los heridos y cadáveres'; amanezquero 'jugador que sacaba solo lo necesario para subsistir de un día para otro'; arrastradero 'lugar de juego de baja estofa'; boquetero 'portero en las cárceles que registraba a los presos recién llegados'; cucharero 'ladrón'; galerón 'en una cárcel, sala ocupada por reclusos'; ganzuero 'ladrón que abría los candados con ganzúas'; garrotero 'salteador armado con un garrote y que atacaba solo a los pasajeros indefensos'; gurupiada 'paga que se le daba al gurupié'.

En lo que atañe a la derivación verbal, son cuatro las voces en cuestión: bolsear 'robar <alguien> el dinero de la bolsa [de una persona]'; carnear 'herir o matar <alguien> [a una persona] con arma blanca'; cajearse 'contraer <el jugador> deudas con el banquero'; coyotear 'actuar < alguien> en las cárceles como coyote (intermediario fraudulento)'.

Otro proceso de enriquecimiento léxico muy frecuente, y no solamente en ámbitos de lenguajes especiales, son los del cambio de significado. No hemos localizado en nuestro pequeño inventario ninguna metonimia, pero sí trece metáforas. Hemos seguido en su clasificación la tipología de Lakoff y Johnson (2003) que ya ha sido aplicada antes con éxito por Sanmartín Sáez (1998) en su estudio sobre el argot español contemporáneo: las metáforas ontológicas, las estructurales y las orientacionales, que no obstante, tienen poca productividad en el argot y aquí no se atestiguan.

En cuanto a las estructurales, es decir, cuando un concepto se organiza metafóricamente con términos de otro (un objeto, un animal, etc.), son ocho en total: aire 'la salida de dos cartas de igual clase'; amanezca 'los primeros gastos del día'; caja 'el dinero que presta el montero a un jugador'; chica 'la carta de menor valor'; chinche 'cárcel'; golpe 'portero'; coyote 'intermediario fraudulento'; flechar 'apostar sin miedo en el juego'.

Las metáforas ontológicas, es decir, las que representan acontecimientos, actividades, emociones, ideas, etc., como entidades y sustancias, son cinco: calificación 'soltar < las autoridades $>$ arbitrariamente a un reo aprehendido durante el día'; caridad 'comida de la cárcel'; completarse 'hurtar < una persona> para cubrir una parte de sus gastos'; compurgar 'cumplir <un reo > una parte de su condena'; evadirse 'huir <una persona> de un lugar cerrado, sobre todo de una prisión'. 


\subsection{Fuentes de ejemplos utilizadas en el Vocabulario}

Si prestamos atención a los ejemplos utilizados por García Icazbalceta para avalar el uso de los términos argóticos, nos damos cuenta enseguida de que la mayoría procedía de fuentes literarias, sobre todo de las novelas de costumbres. En total son 54 ejemplos, pero están divididos de manera desigual.

Los autores más citados son el escritor de prosas costumbristas José Tomás de Cuéllar, que firmaba sus textos bajo el seudónimo de «Facundo», y José Joaquín Fernández de Lizardi, que en el Vocabulario aparecía como «Pensador», es decir, bajo la forma abreviada de su pseudónimo «El Pensador Mexicano» con que solía firmar sus artículos periodísticos. Ambos autores aparecen en nuestro pequeño corpus con quince citas de sus obras.

Las citas de Facundo procedían, por ejemplo, de la novela de costumbres Los fuereños (calificación, caridad, chinche); de las prosas cortas recogidas en la colección La linterna mágica (amanezca, chinche, araña, carpanta, conclapache, burlote); de sus Artículos ligeros (burlote); o de sus Versos satíricos (chinche). Es bastante común que aparezcan en un solo artículo varias citas de un solo autor, como sería el caso de Facundo.

Como ya hemos dicho, quince citas son de José Joaquín Fernández de Lizardi. La mayoría venía de la novela El Periquillo Sarniento (amanezca, amanezquero, arrastradero, burlote, caridad, cuchara, cucharero, flechar, gurupiada, gurupié); y dos citas procedían de la novela Don Catrín de la Fachenda (amanezquero y gurupié).

Otros escritores citados fueron Luis G. Inclán, autor de la novela de costumbres Astucia. El jefe de los Hermanos de la Hoja o los charros contrabandistas de la Rama, que aparece en seis ocasiones (bartolina, boquetero, carnear, gatazo, burlote, caja); Manuel Payno y su novela El fistol del diablo y sus Crónicas de viaje fueron utilizados en cinco ocasiones (amanezca, abrigador o araña); cuatro veces el uso estaba documentado a partir de la Musa Callejera, de Gabriel Prieto («Fidel») (por ejemplo, chinche) y una vez a partir de Hidalgo de Medellin, de Juan Policarpo (gurupié).

En seis ocasiones García Icazbalceta acudió a ejemplos procedentes de textos que no eran literarios, sino ensayísticos. Se trataba de voces que funcionaban más bien como términos técnicos relacionados con la organización o funcionamiento de la cárcel, como bartolina 'celda de castigo', galerón 'sala grande que servía de cárcel', o compurgar 'cumplir la condena'.

$\mathrm{Y}$ al final, son doce las voces sin documentación textual. En algunas ocasiones son entradas en las que García Icazbalceta se limitaba a explicar las diferencias entre el uso peninsular, documentado en el diccionario 
académico, y el mexicano (evadirse, golpe, aire), mientras que en otras el lexicógrafo traía ejemplos probablemente inventados (bolsear, completarse, abrigadero, cajearse, chica). En otros casos simplemente traía definiciones sin ningún tipo de ejemplificación (afanaduría, coyotear, ganzuero, garrotero). Parecen ser casos de voces para las que sería difícil encontrar ejemplos de uso reales por ser o tecnicismos de la delincuencia, como tipos de oficios (ganzuero, garrotero) o términos de juego (aire, cajearse, chica, etc.) y García Icazbalceta se basaba aquí probablemente tan solo en su propia competencia léxica. Serían, por tanto, importantes documentos de su uso (o por lo menos de su existencia) en el español mexicano de la época. Huelga decir que para la mayoría de estas voces falta también la documentación lexicográfica.

\subsection{División temática de áreas del argot en el Vocabulario}

La división temática del argot de la delincuencia presente en el Vocabulario se puede hacer tan solo de modo general, puesto que las voces son relativamente pocas. Como ya hemos dicho, son 36 en total y las hemos dividido en cuatro grupos.

El primero está formado por palabras que pertenecían al ámbito de la cárcel. Son el subgrupo más numeroso (doce). Se recogen aquí términos que podríamos llamar «técnico-administrativos», es decir, los que designaban espacios o dependencias que había en las prisiones (afanaduría, bartolina, galerón), empleos (boquetero, golpe ${ }^{2}$ ) y serían más bien estilísticamente neutros, ya que a partir de los ejemplos no parece que fueran diafásicamente marcados (calificación, compurgar, evadirse, caridad). En este sentido es muy llamativo el caso de la voz caridad 'comida de la cárcel', término empleado por la administración, ya que los reclusos, según hemos visto en otros estudios (Buzek 2018 y 2019), se referían a ella con el término pantofacia. En general podemos decir que son pocas las voces probablemente nacidas entre los presos, propias de ellos y manejadas por ellos. Las únicas podrían ser coyote y coyotear (coyote 'llaman [ellos, es decir, los presos] al zángano que se introduce en las cárceles [...])', o chinche 'daba el pueblo este nombre [...]', en cuya definición el lexicógrafo hacía alusión a su origen popular.

El segundo grupo lo comprenden voces que podríamos considerar como propias del léxico de la delincuencia (nueve). Se trataba de profesiones de delincuentes (cuchara, cucharero, ganzuero, garrotero), acciones que cometían (completarse, bolsear, carnear, echar gatazo) o lugar al que acudían (arrastradero), y en su caso sí se nota que se habían creado entre ellos.

2 Como hemos visto (Buzek, 2018 y 2019), los golpes no eran empleados sino reclusos, y dentro de la jerarquía de los presos no tenían una posición muy prestigiosa. 
Un tipo de argot de la delincuencia bastante especial fue el léxico de los jugadores de cartas, como ya hemos visto en Buzek (2017). Puesto que una de las fuentes que manejaba García Icazbalceta eran las novelas de El Pensador Mexicano, y sobre todo El Periquillo Sarniento, no sorprende que estos términos hayan entrado también en el Vocabulario de mexicanismos. Por otra parte, El Periquillo no fue la única fuente: se citaban también otras obras costumbristas posteriores o aparecían ejemplos inventados, lo que podría dar a entender que serían voces vigentes y usadas en el ámbito del juego (fraudulento) en la época del lexicógrafo. Son ocho términos en total y salvo dos excepciones (aire, chica) están bien documentados (burlote, caja, cajearse, flechar, gurupiada, gurupié).

$\mathrm{Y}$ al final tenemos un grupo de siete palabras argóticas en tránsito, es decir, voces probablemente originarias entre los grupos marginales mexicanos de la época, pero que ya se habían abierto paso en el habla de las clases urbanas populares y llegaron a formar parte de lo que hoy llamaríamos el argot común mexicano (abrigadero, abrigador, amanezca, amanezquero, araña, carpanta, conclapache). Este hecho lo deducimos a partir de las citas, pero también porque faltaban en los diccionarios mexicanos del argot de la delincuencia, aunque es cierto que la documentación lexicográfica, y sobre todo en casos como este, debe ser tratada con sumo cuidado.

\section{Conclusión}

El objetivo de esta contribución ha sido estudiar el léxico argótico presente en las páginas del Vocabulario de mexicanismos, obra póstuma de Joaquín García Icazbalceta. Hemos prestado atención a voces que el lexicógrafo identificaba con el habla carcelaria y con el sociolecto de la delincuencia con el objetivo de ver qué tipos de voces entraban en las páginas del diccionario y cuáles serían sus razones para incluirlas.

Hemos llegado a la conclusión de que, desde el punto de vista de la lexicología histórica, la mayoría de los términos son patrimoniales y la presencia de indigenismos y demás préstamos es mínima. En ello coincidimos con otros estudios del argot, tanto mexicano como de otras áreas del español. En lo que se refiere a los procesos lexicogenéticos, ha sido frecuente la derivación y el cambio de significado. Si contrastamos las voces con los repertorios lexicográficos del argot mexicano y con los diccionarios de americanismos, de mexicanismos y con el diccionario integral del español en México, vemos que una parte significante de ellos, aproximadamente un tercio, sí se recoge en estos diccionarios $y$, por tanto, podríamos decir que formaría parte no tanto del argot en el sentido restringido, sino más bien del argot común mexicano de aquel entonces. Para el resto de las voces no tenemos documentación lexicográfica y tenemos que confiar en la competencia léxica del autor. 
Una de las características más destacadas del Vocabulario es el hecho de ser un diccionario con citas. Si prestamos atención a ellas, nos damos cuenta de que la mayoría procedía de las novelas de costumbres de la época. Por tanto, el argot de la delincuencia que se abrió paso a las páginas del diccionario fue el argot "con proyección literaria» y en este sentido el argot mexicano del siglo XIX, tal como quedó reflejado en el diccionario a través del prisma de sus fuentes, guardaba ciertas similitudes con la germanía española de los Siglos de Oro, que también había sido recogida a partir de fuentes literarias. No obstante, aunque no podemos estar plenamente seguros de que dichas voces pertenecieran al argot de la delincuencia vigente en aquel entonces, creemos que podemos admitir que, para cumplir con la función de identificar a los personajes en dichas obras literarias como tipos sociales, los términos argóticos debían ser reconocibles como tales por el público.

Finalmente, hemos localizado en el diccionario varias voces que, o bien no venían acompañadas de ninguna documentación textual o llevaban tan solo ejemplos inventados. En ocasiones tampoco hemos encontrado para ellas documentación lexicográfica. En este caso, si hemos de fiarnos del instinto idiomático del autor, se trataría de voces que tendrían el potencial de ser representantes del auténtico argot de la delincuencia mexicana de la época. Nuestro corpus es demasiado pequeño como para poder aventurarnos a formular una hipótesis, pero nos da la impresión de que cuanto más «especializada» es la voz (garrotero, ganzuero, aire, chica), menos documentación tenemos para ella tanto dentro como fuera del diccionario, en los repertorios de control.

En síntesis, creemos que el diccionario de Joaquín García Icazbalceta ha cumplido con nuestros objetivos. Es un diccionario que había sido planeado como un repertorio con citas para poder ejemplificar las acepciones que traía basándose en las fuentes mexicanas de la época. Y aunque las fuentes son muchas veces literarias, ello no les quita autenticidad, sino más bien aporta otra información añadida sobre el alcance y el nivel de conocimiento de esta parcela del léxico en el español mexicano a finales del siglo xix.

\section{BibliografíA}

Academia Mexicana de la Lengua (1886): Memorias de la Academia Mexicana, tomo ini. México, Impr. Francisco Díaz de León (en línea: <http://www.academia.org.mx/ aml_static/memorias/tomo3/tomo3.html> [consulta: 20 de mayo de 2018]).

Aguilar, J.R. (1941): Los métodos criminales en México. México, Ediciones Lux.

Alonso Hernández, J.L. (1977): Léxico del marginalismo del Siglo de Oro. Salamanca, Universidad de Salamanca.

Amor, R. (2014 [1947]): Diccionario del hampa. Monterrey, Universidad Autónoma de Nuevo León. 
Bürki, Y. (2014): «Darío Rubio: ¿La anarquía del lenguaje en la América española? Hacia el reconocimiento del léxico americano y del mexicano en particular». Boletín Hispánico Helvético, 23, págs. 195-226.

BuzeK, I. (2011): «Argot: historia documentada de un término en la lingüística española». Moenia, 17, págs. 289-302.

- (2015): «Diccionario de mejicanismos de Féliz Ramos i Duarte (1895): fuente para la historia del léxico de origen gitano en el español mexicano». Revista Internacional de Lingüistica Iberoamericana, 26, págs. 125-144.

- (2017): «El léxico de las clases bajas en El Periquillo Sarniento». En Carpi, E. y García Jiménez, R.M. (eds.): Herencia e innovación en el español del siglo XIX. Pisa, Pisa University Press, págs. 45-74.

- (2018): «El léxico carcelario mexicano durante el porfiriato y su lexicografía oculta: un estudio de caso». Boletín de Filología, 53.1, págs. 35-61.

- (2019): «El argot carcelario mexicano del siglo XIX en la literatura costumbrista: el caso de La Chaquira (Belén por dentro)». Boletín de Filología, 54.1, págs. 39-64.

- (2020): «Actitudes lingüísticas en el Vocabulario de mexicanismos de Joaquín García Icazbalceta (1899)». Nueva Revista de Filología Hispánica, 68.2 (en prensa).

Buzek, I. y Gazdíková, K. (2017): «El léxico carcelario en el Diccionario de mejicanismos de Féliz Ramos i Duarte». Hesperia, 20.1, págs. 99-109.

Chabat, C.G. (1964): Diccionario de caló: el lenguaje del hampa en México. México, F. Méndez Oteo-Librería de Medicina.

Chamorro, M.I. (2002): Tesoro de villanos: lengua de jacarandina: rufos, mandiles, galloferos, viltrotonas, zurrapas, carcaveras, murcios, floraineros y otras gentes de la carda. Barcelona, Herder.

Colín Sánchez, G. (1997 [1987]): Así habla la delincuencia. México, Porrúa.

Company, C. (2012): «El español del siglo xviı. Un parteaguas lingüístico entre España y México». En García-Godoy, M.T. (ed.): El español del siglo XviII. Cambios diacrónicos en el primer español moderno. Bern, Peter Lang, págs. 255-291.

da = Asociación de Academias de la Lengua Española (2010): Diccionario de Americanismos. Madrid, Santillana.

Davis, J.E. (1950): «Mexican Spanish and El Periquillo Sarniento». Arizona Quarterly, 6, págs. 250-255.

- (1956): Estudio lexicográfico de El Periquillo Sarniento. Tesis doctoral. Tulane University.

- (1958): «Algunos problemas lexicográficos en El Periquillo Sarniento». Revista Iberoamericana, 23.45, págs. 163-171.

DEM = LARA, L.F. (dir.) (2010): Diccionario del español de México. México, El Colegio de México.

DM = Company, C. (dir.) (2010): Diccionario de mexicanismos. México, Academia Mexicana de la Lengua.

Fernández Gordillo, L. (2010): «Las obras representativas de la lexicografía diferencial de México en el contexto hispanoamericano y sus recepciones en el DRAE». 
En Ahumada, I. (ed.): Metalexicografía variacional. Diccionarios de regionalismos y diccionarios de especialidad. Málaga, Universidad de Málaga, págs. 107-128.

Frago Gracia, J.A. (2014): «Estampas sociolingüísticas del español de México en la Independencia, I: el indio bilingüe, el marginal y la mujer». Boletín de Filología, 49.1, págs. 37-57.

Franco, J.L. (2014 [194?]): El Canerousse. Monterrey, Universidad Autónoma de Nuevo León.

García Icazbalceta, J. (1899): Vocabulario de mexicanismos comprobado con ejemplos y comparado con los de otros países hispano-americanos. México, Tip. y Lit. La Europea.

Hernández Martínez, L. (2002): «De lenguajes juveniles urbanos. La formación de conceptos en caló». En Nateras, A. (ed.): Jóvenes, culturas e identidades urbanas. México, Universidad Autónoma Metropolitano-Iztapalapa, págs. 61-73.

- (2004): «A propósito de la violencia del argot». Razón y Palabra, 39 (en línea: $<$ http://www.razonypalabra.org.mx/anteriores/n39/lhernandez.html> [consulta: 20 de mayo de 2018]).

Lakoff, G. y Johnson, M. (2003 [1980]): Metaphors we live by. Chicago, University of Chicago Press.

LARA, L.F. (1992): «El caló revisitado». En Luna Traill, E. (ed.): Scripta Philologica in Honorem Juan M. Lope Blanch a los 40 años de docencia en la UNAM y a los 65 años de vida. Lingüistica española e iberoamericana. México, unAM, vol. II, págs. 567-592.

- (1997): Teoría del diccionario monolingüe. México, El Colegio de México.

López y López, M. (1931): «Modismos y refranes del "Periquillo Sarniento"». Revista de la Universidad de México, 6, págs. 462-482.

NTLLE = Real Academia Española. Nuevo Tesoro Lexicográfico de la Lengua Española (en línea: <http://ntlle.rae.es/ntlle/SrvltGUILoginNtlle> [consulta: 20 de mayo de 2018]).

Prieto García-Seco, D. (2014): Cuatro siglos de lexicografía española. La recepción de Tirso de Molina en los diccionarios del español. A Coruña, Universidade da Coruña.

Salillas, R. (1896): El delincuente español. El lenguaje. Madrid, Libr. Victoriano Suárez.

Sanmartín Sáez, J. (1998): Lenguaje y cultura marginal: el argot de la delincuencia. València, Universitat de València.

- (2006): Diccionario de argot. Madrid, Espasa.

\section{Anexo}

Voces del argot de la delincuencia recogidas en Vocabulario de mexicanismos

(1) $\uparrow$ Abrigadero. m. Lugar adonde acude y se oculta gente de mal vivir. Ese monte es un ABRIgADERO de ladrones: tal cosa es un ABRIgADERO de pillos. También hablando de animales: ABRIGADERo de chinches, de pulgas.

[Documentación lexicográfica: Chamorro, 2002: Abrigo 'Amparo, protección, defensa, patrocinio, consejo'; cf. $D A$ : $M x$. obsol. 'Doblez de la ropa en donde se ocultan chinches y pulgas. rur.'; $D M$ : rur. 'Doblez de la ropa en donde se ocultan chinches'] 
(2) Abrigador, ra. [...] 2. m. Encubridor, el que ampara, oculta ó defiende á otro: tómase siempre en mala parte.

«No quiero que digan mis compañeros, que soy un abrigador de macutenos» (PAyno, Fistol, tomo III, cap. 2).

[Sin documentación lexicográfica]

(3) Afanaduría. f. En las cárceles, hospitales, é inspecciones de policía, la pieza en que se reciben heridos ó lastimados, y se les da la primera curación, se depositan los cadáveres que llegan, etc.

[Sin documentación lexicográfica]

(4) $\uparrow$ Aire. m. En el juego del monte se llama así la salida de dos cartas de igual clase, como dos reyes, dos sotas \&c, cuando se sacan para el albur. (V. en el Dicc. Encuentro, 5. acep.)

[Sin documentación lexicográfica]

(5) Amanezca. f. fam. El amanecer. Usado por los pobres con referencia á los primeros gastos del día, y suelen decir: con esto tengo para la AmANEzca.

«Lo primero que hago es rehundir y esconder seis ú ocho realillos para la amanezca, de la primera ingeniada que tengo" (Pensador, Periquillo, tomo II, cap. 2, pág. 37) — «Será probablemente un pobrete que, como dice esta gente de juego, viene á sacar la amanezca» (PAyno, Fistol, tomo I, cap. 26) — «¿ué anda Vd. haciendo? Nada, os dice un barbón: ando tras de la amanezca» (FAcundo, Isolina, tomo II, cap. 12, pág. 206) — «Pues vea Vd., señor; á lo menos se vive, se busca la amanezca» (ÍDEM, Gabriel, tomo I, cap. 9).

[Sin documentación lexicográfica]

(6) Amanezquero. m. fam. El que no tiene oficio ni beneficio, y saca del juego ó del otro mal arbitrio lo necesario para pasar cada día. Desusado hoy.

«Yo no pasaba de lo que llaman amanezquero: apenas afianzaba dos ó tres pesos, los rehundía, sacaba mi puro, y me lo iba á chupar á la calle» (Pensador, Catrín, cap. 7, pág. 221).

[Sin documentación lexicográfica]

(7) † Araña. f. Mujer pública, ramera.

«iArre! atrevidote! ¿Te figurarás que soy una de esas arañas de la calle?» (PAYNo, Fistol, tomo II, cap. 12) - «Dejando á un lado esa multitud de mujeres sin poesía y llenas de defectos físicos y morales, que con tanta gracia y propiedad han designado nuestros calaveras con el epíteto de arañas» (ÍDEM, Veracruz, 5) - «Allí vive una persona que... yo no creo que Vd. la busque. — ¿Por qué? —Porque es arañita. Cállate, muchacho, y no seas quitacréditos: ¿qué sabes tú de eso? —Quiero decir, ella es muy guapa y es güera; pero no por eso deja de ser arañita» (FAcundo, Jamonas, tomo I, cap. 16) - «Bajo este punto de vista, lo de la vista gorda respecto á arañas, á borrachos y á jugadores es una actitud profundamente filosófica» (ÍDEM, La Evolución Social, pág. 285). 
Dióse acaso este nombre á las mujeres públicas, porque andan tras la mosca (dinero). Parece confirmar esa creencia el estribillo de una letrilla satírica de Quevedo: «Y eras araña que andabas / Tras la pobre mosca mía» (Edic. Rivadeneyra, Terpsichore, n. ${ }^{\circ}$ 327).

[Documentación lexicográfica: Alonso Hernández, 1977: 'Buscona'; DRAE-1884: 8. Méj. 'Mujer pública's; DM: despect. 'Mujer libertina'; DEM: (Popular) 'Prostituta']

(8) † Arrastradero. m. Juego de trucos ó garito de baja estofa. Desusado ya.

«Otras [noches], que son las más, las paso en los arrastraderitos. —¿Y cuáles son los arrastraderitos? - Los arrastraderitos son esos truquitos indecentes é inservibles que habrás visto en algunas accesorias» (Pensador, Periquillo, tomo II, cap. 2, pág. 35) - «En fin, en dichos arrastraderos...se roba, se bebe, se juega, se maldice, se reniega» — «Si antes estaba yo cuidadoso con la pintura que me hizo con la videta cocorina, después que le dió los claros y las sombras que le faltaban con lo de los arrastraderos, me quedé frío (íDem, ibídem, pág. 36).

[Sin documentación lexicográfica]

(9) Bartolina. f. Calabozo estrecho, oscuro é incómodo.

«Se providenció por S. E. que la Nobilísima Ciudad diese sitio competente para fabricar una casa [cárcel] con las viviendas necesarias, calabozos, bartolinas, pulguero y demás necesarias» (Diario de Castro Santa-Anna, 1757, tomo ini, pág. 123) — «A la presidenta de la cárcel la metieron en una bartolina» (Diario del Alabardero, 1782, pág. 145) - «Mandó el Sr. Virrey Gálvez que sacaran á D. Pedro Varón, que era cachupín, que estaba también en capilla, el cual estuvo ocho horas, y lo metieron en una bartolina» (ídem, 1784, pág. 189) — «Su franqueza le valió su primera persecución política, pasando algún tiempo en la ex-Inquisición en la bartolina llamada del Diablo» (ZARco, pról. al Gallo Pitagórico, p. viri) — «Una horrorosa bartolina que por su hediondez, poca luz y sabandijas en que abundaba, había quedado en total abandono» (Astucia, tomo II, cap. 7 bis, pág. 227).

[Documentación lexicográfica: Franco, 2014 [194?]: 'Calabozo; aposento de la cárcel'; DA: $M x, G u, H o, E S, N i$. obsol. 'Celda estrecha e incómoda, generalmente de castigo, de una prisión o dependencia policial'; $D M$ : ídem.; DEM: 'Celda estrecha, oscura y muy incómoda: las sórdidas bartolinas de la antigua cárcel de Belén’]

(10) $\uparrow$ Bolsear. a. Extraer del bolsillo de alguno el ladrón ratero las monedas ú otros objetos. A fulano lo BolseAron ayer en la Catedral.

Guatemala. Batres, pág. 138.

[Documentación lexicográfica: Franco, 2014 [194?]: 'Quitar a alguien lo que tenga de valor'; Colín Sánchez, 1997 [1987]: 'Robar sustrayendo de los bolsillos, flojear, haraganear'; $D A: M x, G u, H o, E S, N i, C R, A r$. 'Robar una persona dinero a alguien del bolsillo'; $D M$ : 3. coloq. 'Robar alguien el dinero de la bolsa de una persona']

\footnotetext{
3 Incluida probablemente por descuido; la acepción faltaba en el DRAE-1869.
} 
(11) Boquetero. m. Empleado de las cárceles que, colocado en el primer postigo ó boquete, registra á los presos que llegan y los introduce al edificio.

«¡Ahí va ese reo! gritó otra vuelta el boquetero» (Astucia, tomo II, cap. 7 bis, pág. 217).

[Sin documentación lexicográfica]

(12) Burlote. m. Entre los jugadores, el monte ó partida más pequeña, que alguno de ellos pone, acabada por cualquier motivo la primera.

«Se puso á tallar, diciendo: tírenle á este burlotito» (Pensador, Periquillo, tomo II, cap. 3, pág. 44) — «Señores, si á Vdes. les parece, pondremos burlote: yo las tejo. —Sí, sí, contestaron, burlote» (Astucia, tomo I, cap. 9, pág. 161) — «La mamá, que conocía el burlote, y que se preciaba de saber jugar, adicionó el proyecto» (FAcundo, Venus, Birján, $\mathcal{E}^{2}$., II, 77).

En Cuba Borlote (Pichardo, pág. 47; Macías, pág. 187).

[Documentación lexicográfica: Chamorro, 2002: Burloteros 'Eran las personas que arrendaban al coimero después de la media noche para seguir jugando. De burlote 'banca de jugadores de poco fondo'; Salillas, 2/1896 'Partida de juego de poca cuantía en el juego de banca o monte']

(13) † Caja. f. En el juego del monte (ó sea albures), el dinero que presta el montero á un jugador abonado que ha perdido cuanto traía, y quiere seguir jugando. Las CAJAs no se aseguran con documento alguno, y deben quedar pagadas dentro de veinticuatro horas, porque se consideran como deudas de honor.

«Empecé á abrir caja...y á las doce de la noche tenía ya ochocientos y pico de pesos en dinero, y cuatrocientos en cajas» (Astucia, tomo I, cap. 9, pág. 161) — «La protección consistía en cajas en el juego» (FAcundo, Fuereños, xv).

[Sin documentación lexicográfica]

(14) Cajearse. pr. Contraer el jugador deudas con montero. Perdió todo, y se cajeó, ó salió CAJEADo, en mil pesos.

[cf. Chabat 1964: cajiarse 'comprometerse, endrogarse']

(15) † Calificación. f. Llámase así en México á cierta distribución (no sé si legal) que acostumbra hacer cada noche el Gobernador del Distrito Federal, ó su secretario, de los reos de delitos no graves ó de infracciones de policía, que han sido aprehendidos en el día, y á su arbitrio suelta á unos, impone á otros ciertas penas y envía al resto á la cárcel, consignados al juez de turno.

«Es seguro que se queden allí á esperar la calificación, y mañana temprano, ó van á Belén [la cárcel] ó salen en libertad» (FAcundo, Fuereños, Xvini).

[Sin documentación lexicográfica]

(16) † Caridad. f. Dase todavía este nombre á la comida que se ministra en las cárceles á los presos, porque antiguamente no se les daba ninguna, y había personas caritativas que andaban pidiendo limosna para el sustento de los encarcelados desvalidos que no tenían familia ó amigos que los socorriesen. Pero hasta hoy se 
tiene por muy desdichado al pobre preso que no cuenta con más alimento que la comida oficial, es decir, la CARIDAD, que ya no lo es.

«Ellos engullían muy bien, tanto por no estar acostumbrados á mejores viandas, como por ser éstas de las que les daba la caridad; pero yo apenas las probaba, de manera que si no hubiera sido por un bienhechor que se dignó favorecerme, perezco en la cárcel de enfermedad ó de hambre» (Pensador, Periquillo, tomo II, cap. 8, pág. 136) — «El contratista, el abastecedor de reclusos é indefensos consumidores de la carne de la caridad» (FAcundo, Fuereños, pág. 168).

Covarrubias dice que en algunas partes llaman á CARIDAD «cierta refección que se da de pan, vino y queso en los entierros y honras de difuntos».

[Sin documentación lexicográfica]

(17) Carnear. a. vulg. Herir y matar con arma blanca en un combate ó alcance.

«Voltearon caras, se hicieron bolas, y los carnearon bonitamente, lanceándolos y correteándolos un gran trecho» (Astucia, tomo II, cap. 7 bis, pág. 199).

[Documentación lexicográfica: $D A: M x, B o$; $C h$, delinc.|metáf. 'Herir y matar a una persona con arma blanca'; $D M$ : 'Matar a una persona con arma blanca']

(18) Carpanta. f. Pandilla, trulla de gente alegre y maleante.

«De esos pollos que empluman en chiribitil y se exhiben en día menos pensado, ingresando sin ceremonia á la carpanta» (FACundo, Ensalada de Pollos, tomo II, cap. 6).

[Sin documentación lexicográfica]

(19) $\uparrow$ Chica. f. En el juego del monte la carta de menor valor comparativo, como el as respecto del dos, éste respecto del tres \&c. hasta llegar al rey que es la mayor. Se hizo la cHica, ganó la carta de menos valor.

Cuba. Pichardo, pág. 121, art. Chico; Macías, pág. 128.

(20) † Chinche (La). f. Daba el pueblo este nombre á la antigua cárcel municipal, porque en efecto estaba plagada de esos bichos á un grado increible.

«Míralas, míralas, decía otro, y van de baile á la chinche» (Facundo, Fuereños, XVIII) - «El caso es que á estas horas están en la chinche. - Mientras ellos están en la chinche, las niñas...pues, se están divirtiendo» (ÍDEM, ibídem, xvini) «Adiós, dijo el herrero, ya este barrió con los otros á la chinche» (Ídem, Gabriel, tomo II, pág. 128) — «Le llama á la prisión chinche ó chirona» (FAcundo, Abuso de la chanza) - «Vamos, la chinche os espera»(G. Prieto, Musa callejera, Romance leperusco, pág. 220) — «Y se fué para la chinche / Silencioso y cabizbajo» (ÍDEm, ibídem, Romance, pág. 297) — «Aunque los diablos me lleven / Y remanezca en la chinche» (ÍDEM, ibídem, pág. 300) — «A la chinche me los llevo» (ÍDEM, ibídem, Pepa y el tuerto, pág. 317).

[Documentación lexicográfica: Colín Sánchez, 1997 [1987]: 'Cárcel']

(21) † Completar. [...]. 2. Completarse. pr. fam. Hurtar para cubrir una parte del gasto. Fulano gana un sueldo corto; pero se completa con las buscas.

[Sin documentación lexicográfica] 
(22) † Compurgar. a. Cumplir un reo la pena de prisión temporal á que fué sentenciado, con lo cual queda extinguida la acción. Es común en las causas criminales absolver al reo, dándole «por compurgado con la prisión sufrida» durante la sustanciación del proceso.

«Fué preso y conducido á una fortaleza, hasta que compurgó su exceso» (Beaumont, Crón. de la Prov. de Mich., pte. I, lib. 2, c. 11).

[Documentación lexicográfica: DRAE-18844: 'Pasar por la prueba de compurgación el acusado, para acreditar por este medio su inocencia'; cf. $D A$ : Ho. 'Purgar o pagar alguien una pena o pecado'; DEM: (Der) 'Cumplir un preso la condena a la que fue sentenciado']

(23) Conclapache. com. voz baja. Compinche; tomado casi siempre en mala parte.

«Vaya...al Chino yo le sé los pasos, y semos conclapaches» (FACundo, Nochebuena, cap. VIII).

[Documentación lexicográfica: Colín Sánchez, 1997 [1987]: 'Amigo, compañero'; $D A: M x$. 'Compinche. desp.'; DM: V. contlapache. 'Compinche, encubridor'; DEM: V. contlapache. 'Persona amiga de alguien, que lo apoya o encubre en una mala acción']

(24) * Coyote. [...]. Coyote llaman también al zángano que se introduce en las cárceles y estafa á los presos embaucándoles con alardes de valimiento y ofertas de obtenerles gracias.

«Ningún ramo judicial extranjero despacha, en proporción á otros asuntos, mayor número de juicios por deudas, que los que se versan en ese hormiguero de tinterilleros, coyotes, víctimas y verdugos» (FAcundo, Víctimas del pulpo, pág. 143).

[Documentación lexicográfica: Franco, 2014 [194?]: 'Persona que se encarga oficiosamente de hacer trámites legales sin ser abogado'; Colín Sánchez, 1997 [1987]: 'Intermediario en transacciones, no siempre lícitas, entre autoridades y delincuentes'; DEM: (Coloq.) 'Persona que hace de intermediario, sacando provecho de ello abusivamente, para arreglar asuntos, a veces ilegales, en oficinas de gobierno o de cuestiones administrativas, en cambios de moneda, operaciones de bolsa']

(25) Coyotear. n. Ejercer en las cárceles el mal oficio de coyote.

[Documentación lexicográfica: Franco 2014 [194?]: 'Actuar como coyote']

(26) † Cuchara. [...] 2. fam. Cucharero, ladrón ratero.

«Preguntaron sus soldados á mis conductores que por qué me llevaban. Y ellos respondieron que por cuchara, esto es, por ladrón» (Pensador, Periquillo, tomo II, cap. 5, pág. 78).

[Sin documentación lexicográfica]

${ }^{4}$ Las referencias a diccionarios generales del siglo xIx, tanto académicos como extraacadémicos, proceden del Nuevo Tesoro Lexicográfico de la Lengua Española (NTLLE). 
(27) † Cucharero. m. Ladrón ratero. Usábase mucho; hoy se oye rara vez.

«En estos socuchos juegan los pillos, cuchareros y demás gente de la última broza» (Pensador, Periquillo, tomo in, cap. 3, pág. 36) — «Cátenme Vds. ya cofrade de semejante comunidad, miembro de una academia de pillos, y socio de un complot de borrachos, tahures y cuchareros» (ÍDEM, ibídem, tomo II, cap. 4, pág. 67) — «La patente se le pide, y si no quieres pagarla, harás la limpieza, so cucharero» (ÍDEM, ibídem, tomo II, cap. 5, pág. 80).

[Sin documentación lexicográfica]

(28) † Evadirse. pr. Fugarse; escaparse de un encierro, de una prisión. Ortuzar dice que falta en el Diccionario. Éste, en efecto, nos enseña que EVADIR significa «evitar un daño ó peligro inminente: eludir con arte y astucia una dificultad prevista»: es decir, que Evadirse será nada más precaverse de un mal lance, antes de caer en él, y acá entendemos, además, que es salir de un mal lance, como el de haber sido encarcelado, después de haberle sufrido. En lo cual vamos casi de acuerdo con el Diccionario de Autoridades, donde se lee que Evadir es «huir, escapar, y salir de algún peligro, dificultad y lance apretado».

[Documentación lexicográfica: DRAE-1899: 2. 'Fugarse, escaparse'; cf. DEM: Evadirse prnl 'Huir una persona de un lugar, especialmente de donde está encerrada o encarcelada']

(29) † Flechar. a. Salvá da á este verbo, como acepción mexicana, la de «Apostar sin miedo en el juego». Yo no la he oído; mas parece comprobarla el siguiente pasaje.

«No así los que van al juego á flechar el dinero que les ha costado su sudor y su trabajo» (Pensador, Periquillo, tomo iI, cap. 2, pág. 34).

[Sin documentación lexicográfica]

(30) Galerón. m. Galera ó sala grande que suele servir de cárcel.

«Fué aprehendido y remitido al galerón con sus compañeros» (Diario de México, tomo IV, pág. 275).

[Documentación lexicográfica: Franco, 2014 [194?]: Galera. 'En una cárcel, sala ocupada por reclusos. [...]'; cf. DA: $M x$. 'Espacio cerrado muy amplio'; DM: ídem.; DEM: 'Recinto espacioso, generalmente de construcción basta, que se usa como taller, bodega, etc.']

(31) Ganzuero. m. Ladrón que abre cerraduras con ganzúas.

[Sin documentación lexicográfica]

(32) Garrotero. m. [...] 2. Salteador que lleva por única arma un garrote, y sólo acomete á pasajeros indefensos.

[Sin documentación lexicográfica]

(33) † Gatazo. m. [echar gatazo] «Engaño que se hace á uno para sacarle dinero ú otra cosa de valor» (Dicc.) Algo diferente es el sentido que tiene esta voz en la frase echar GATAzo, que es hurtar, arrebatando á excusas alguna cosa, como hace el gato cuando echa la zarpa y huye. 
«Y nada menos por eso tuve empeño en echarle gatazo [al anillo]» (Astucia, tomo II, cap. 1, pág. 12).

[Sin documentación lexicográfica]

(34) † Golpe. m. [...] 2. Damos igual nombre al portero de golpe, que es «el que en la cárcel cuida de una segunda puerta, que suele tener pestillo de ruido para notar cuando se mueve» (Dicc.).

[Documentación lexicográfica: Chamorro, 2002: 3. 'Pestillo'; Salillas, 1/1896: golpeado 'postigo']

(35) Gurupiada. f. Paga ó gratificación que se da al gurupié.

«Este arbitrio suele proporcionar una buena gratificación ó gurupiada» (Pensador, Periquillo, tomo iI, cap. 2, pág. 27).

[Sin documentación lexicográfica]

(36) Gurupié. m. El que en el juego del monte reproduce en otro lugar de la mesa, con cartas despuntadas, el albur que saca el tallador, para que le vean los apuntes distantes y hagan allí sus apuestas; paga las que ganan y recoge las que pierden, y á veces suple al tallador.

En Cuba dicen gurrupié (Pichardo, pág. 187) Macías (pág. 660), cree que es palabra castellana, y que viene de gurupa (o grupa) y de pie. Rivodó (pág. 88), asienta que viene de gurupa. Me parece que es sencillamente corrupción del francés croupier, que significa lo mismo.

«Y á Gestas por gurupié / Lo pondréis, por ser bellaco» (Diario de México, tomo II, pág. 456) — «Mesa grande cuadrada, con dos bujías, carpeta y porción de moneda en oro y plata, colocada al último del foro: el montero y gurrupié se verán sentados... / Cayetana. - ...Digo, amigo, / Don Soplillo, mis diez pesos. / Gurupié. —Aguárdese vd., si quiere, / No he de quedarme con ellos» (El Hidalgo en Medellín, pág. 35) — «Monteros y gurupiés / Que vayan á los avernos...» / «Un gurupié barajando / Es jefe de foragidos, / Que con cuarenta bandidos / A los puntos va robando» (Don Simplicio, tomo II, núm. 7) — «Me proporcionó que fuera su gurupié, ganando dos pesos diarios» (Pensador, Catrín, cap. 7) - «Y aunque no sea franco ni gane, el gurupié no puede perder nunca su trabajo, como no sea tonto» (ÍDEM, Periquillo, tomo II, cap. 2, pág. 27) — «¿Qué tal será la cosa que para acomodarse de talladores ó gurupiés con sus mercedes se hacen más empeños que para entrar de oficial en la mejor oficina» (ÍDEM, ibídem, tomo II, cap. 3, pág. 52) — «os talladores y gurupiés eran personas de importancia» (PAYnO, Fistol, tomo I, cap. 7).

[Documentación lexicográfica: DA: (gurupié) RD. 'En un casino, asistente del banquero'; (gurrupié) Cu. p.u. 'Persona que adula a otra por servilismo o interés. pop.'; cf. Salvá-1846: Méj. El que baraja en las casas de juego, y recoge y paga las apuestas] 